\title{
MAZATEC ONSETS AND NUCLEI
}

\section{Chris Golston and Wolfgang Kehrein}

California State University, Fresno, and Philipps Universität, Marburg

1. Introduction. On the basis of a number of interesting lexical contrasts in the Huautla dialect of Mazatec, Pike and Pike (1947) argued for a highly articulated view of syllable structure in natural language such that segments may be distinctively ordered within an onset or nucleus. More recently, Steriade $(1993 ; 1994)$ has used the same data to argue against complex syllable structure in Huautla; she claims that it is plosives (stops and fricatives) that are complex and that onsets in Huautla are for the most part monosegmental. ${ }^{1}$

We show in this paper that the Huautla data require neither complex syllables nor complex plosives (in Steriade's sense). Phonetically and phonologically motivated repartitionings of distinctive features allow for a simple and elegant solution to a number of apparent asymmetries and complications in earlier analyses. Specifically, we show that Mazatec has simple syllables AND simple plosives; the richness of the system lies in the types of features that can be associated to nuclei and to onsets (Mazatec allows no codas).

Our reanalysis has two further important consequences. First, it makes Huautla Mazatec more like other closely related languages: rather than being the odd man out in Popolocan, we will show that Huautla is quite typical of languages in its family. Second, our analysis makes Huautla less marked in terms of languages outside of Popolocan: the exotic subconstituents of onsets and nuclei argued for by Pike and Pike are not required in our analysis, nor are the exotic subconstituents of plosives argued for by Steriade. All our analysis requires is a basic division into onset and nucleus (or consonant and vowel). We show that the type of constituency argued for by Pike and Pike and by Steriade does not seem to be needed in human languages, at least as far as laryngeal contrasts are concerned. ${ }^{2}$

\footnotetext{
${ }^{1}$ The bulk of this project was carried out as part of Sonderforschungsbereich 282 Theorie des Lexikons, funded by the German Science Foundation. We are indebted to Gene Buckley, Birgit Gerlach, Paul Kirk, Peter Ladefoged, Albert Ortmann, David Rood, Dan Silverman, Donca Steriade, Richard Wiese, and two anonymous $I J A L$ reviewers for their help with the ideas and data presented here. Their generous assistance is not of course an endorsement of the views expressed here and none of them is accountable for any errors or infelicities in the text.

${ }^{2}$ Steriade's proposal is based not only on laryngealized segments but also on nasalized segments. We do not treat the latter here but hope to address them in future work.
}

[IJAL, vol. 64, no. 4, October 1998, pp. 311-37]

(c) 1998 by The University of Chicago. All rights reserved. 0020-7071/98/6404-0001\$02.00 
We begin with our analysis of onsets (2) and nuclei (3) in Huautla. We then compare the analyses proposed by Pike and Pike and Steriade (4) and end with a brief conclusion (5).

2. Onsets. Huautla Mazatec seems to contrast pre- and postaspirated (1) as well as pre- and postglottalized (2) sounds; it also has a class of prenasalized sounds (3), but no postnasalized sounds. ${ }^{3}$ Pike and Pike (1947) transcribe these contrasts as follows:

(1) Preaspiration $h t i^{4} \quad$ 'fish' $h k a^{34}$ 'stubble'

(2) Preglottalization $2 \beta a^{4} \quad$ 'hook' $\mathrm{ja}^{4} \quad$ 'rainbow'

(3) Prenasalization $n t a^{43}$ 'good' $n t s a^{4}$ 'my hand'
Postaspiration

vs. tha $a^{4}$ 'light in weight'

vs. $\quad k h \tilde{a}^{3}$ 'bad smelling'

Postglottalization

vs. $\quad \beta 7 e^{43}$ 'I hit'

vs. $\quad j 7 a^{3}$ 'I carry'

Postnasalization

Such contrasts led Pike and Pike (henceforth PP) to propose that Huautla has fairly complex syllable structure with subconstituents under the onset. Consider $h k a^{34}$ 'stubble' and $k h \tilde{a}^{3}$ 'bad smelling': PP analyze the onsets here as $(h / k)$ and $(k / h)$, respectively, with the laryngeal [h] forming a "satellite" subordinated to the head of the onset [k]. Similarly for glottalized and nasalized onsets: $(? / j),(j / ?),(n / t)$ with the laryngeal or nasal segment subordinated to the stop.

We argue here that "postaspiration" and "postglottalization" in Huautla are better treated as aspiration (breathy voice) and glottalization (creaky voice) of the following vowel. In our analysis it is not the onsets in $7 \mathrm{ja}^{4}$ 'rainbow' and $j 7 a^{3}$ 'I carry' that contrast; what is contrastive in these forms is that the former has a glottalized onset and the latter a glottalized nucleus. A better transcription of the forms in (1)-(3), we argue, transfers the postconsonantal [h] and [?] of PP's analysis to diacritics denoting aspiration and glottalization OF THE FOLLOWING VOWELS:

(4)

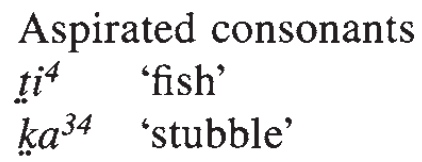

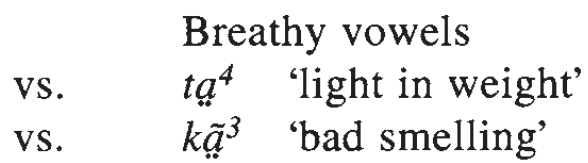

\footnotetext{
${ }^{3}$ Segmental transcription is IPA. Raised digits in PP's transcription mark four distinctive tones with 1 the highest and 4 the lowest (contra usual practice).
} 
(5) Glottalized consonants

\begin{tabular}{ll} 
& \multicolumn{2}{c}{ Creaky voice vowels } \\
vs. & $\quad e^{43}$ 'I hit' \\
vs. & $j a^{4}$ 'I carry'
\end{tabular}

To bring out the parallelism in the analysis we use one diacritic for aspirated onsets and breathy nuclei ([..] for a spread glottis) and one for glottalized onsets and creaky vowels ([ $\sim]$ for a constricted glottis). The new analysis does away with the gap in (3) above in a principled way: the nasal counterpart to breathy vowels and creaky voice is contrastive nasalization, possible on all vowels in Huautla:

(6) Nasalized consonants

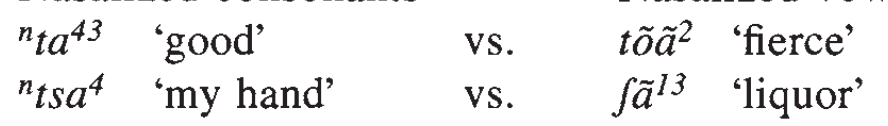

A few autosegmental representations make clearer how our analysis differs from that of PP: 4

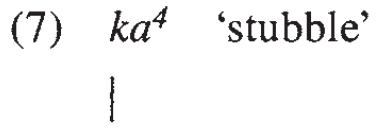

[sg]

(8)

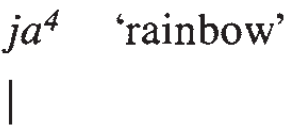

[cg]

(9) $t a^{43}$ 'good'

[nas]

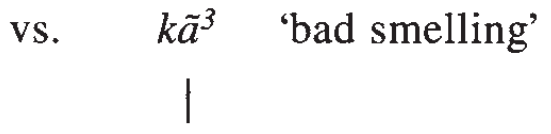

[sg]

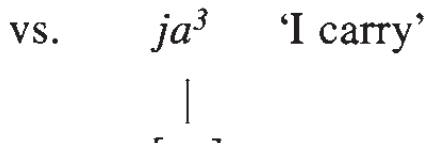

[cg]

vs. toa $^{2}$ 'fierce'

[nas]

An important consequence of our analysis is that Huautla can be analyzed straightforwardly as a language with simple syllabic and segmental structure. Contrary to claims by PP and Steriade, Huautla provides no evidence for any distinctive ordering of segments within onsets nor for any distinctive ordering of features within plosives. The representations in (7)(9) require only the simplest syllabic or segmental representations. In what follows we use onsets and nuclei as the locus of association for distinctive features (Golston and van der Hulst, forthcoming), but our analysis is perfectly compatible with segmental theories of representation. Thus the forms in (7) may be understood as showing a contrast between an aspirated onset and an aspirated nucleus, or as showing a contrast between an aspirated consonant and an aspirated vowel.

${ }^{4}$ Abbreviations are as follows: $[\mathrm{sg}]=$ spread glottis, $[\mathrm{cg}]=$ constricted glottis, [nas] = nasal . 
Our claim is that Huautla onsets (consonants) and nuclei (vowels) are aspirated or not, glottalized or not, nasal or not-no onset (consonant) or nucleus (vowel) in the language admits of a two-way contrast between preand postaspiration, pre- and postglottalization, or pre- and postnasalization.

2.1. Phonetic evidence. $P P$ offer a quite detailed description of what they actually heard when transcribing [C?V] and $[\mathrm{ChV}]$, but their description does not support their analysis. They analyze them as three-segment strings, ( $C$ ?) $V$ and $(C h) V$, with complex onsets. Steriade analyzes them as three-segment strings underlyingly $(C$ ? and $C h V)$ and as two-segment strings on the surface $\left(C^{7} V\right.$ and $\left.C^{h} V\right)$, with complex segments but simple onsets. We analyze them as simple syllables with laryngealized nuclei $(C V$ and $C V$ ). As we shall now see, PP's description provides clear support for our analysis.

We begin with what PP transcribe as [C?V]. Their discussion is worth quoting in full here because it shows that postconsonantal laryngeal features are usually realized on the vowel, not on the preceding consonant:

The glottal stop? at times is actualized as a complete stop, and at other times optionally as a laryngealization (or 'glottalization') of the following vowel. When ? is the second member of a consonant cluster, a vowel which follows it phonemically may phonetically have a slight pre-articulation before the ?.... (1947:79)

[T] here is usually a very slight open transition between the stop and the ? in the same syllable, so that the stops are not phonetically glottalized-i.e., they are not made with egressive pharynx air; and this phonetic gap between the stop and the ? in clusters is often further accentuated in that? may be actualized as the laryngealization of the following vowel rather than as a separate complete stop, while often there is a slight pre-articulation of the vowel before the ? (but after the oral stop in the sequence of oral plus glottal stop). $(1947: 81)$

In short, postconsonantal glottalization in Huautla varies from [t?a] to [ta] to [ta?a] but is never realized as *[t'a]. In the first instance, [t?a], we have no way of knowing whether the glottal pulse is associated to the onset or to the nucleus because it occurs after the release of the consonant but before the articulation of the vowel. But when glottalization is realized on the following vowel [ta], and especially when it is flanked on either side by a modal (clear-voiced) rendition of the vowel [ta?a], the simplest analysis has the glottalization associated to the nucleus. And since onset consonants are NEVER phonetically glottalized, there is no reason to think that glottalization is a feature of the onset.

We are not arguing about what PP heard but about the best way to analyze it: they report that glottalization occurs at the beginning or middle of 
a vowel but never during consonantal release. The simplest analysis of such a state of affairs is that the feature is timed to occur sometime during the nucleus. Further support for such an analysis can be found throughout the entire Otomanguean family of languages. Interrupting glottal stops are found in three of the seven families of Otomanguean: Popolocan, Mixtecan, and Zapotecan. On the basis of this Gudschinsky (1959) posits initial, final, and interrupting glottals for Proto-Popolocan; Longacre (1957) reconstructs the same for Proto-Mixtecan; and Rensch (1976:45) posits interrupted vowels in the Zapotecan languages Proto-Chatino and Isthmus Zapotec. (For a comprehensive discussion of Otomanguean comparative phonology, see Rensch 1976.)

Similar facts obtain for what PP transcribe as [ChV], where the laryngeal feature is realized as a breathy copy of the nucleic vowel: the "phoneme $\mathrm{h}$ takes many forms: before vowels or $\mathrm{y}$, it assumes their shape" (1947:80). Thus, PP's [tha] is a broad approximation to something which could be more narrowly transcribed as [taa ] (voiceless) or [taa (breathy). As this is the only phonetic information PP provide on their [ChV] transcriptions, we do not know whether a further lag of voicelessness or breathiness, i.e., "a slight pre-articulation of the vowel" before the $h$, may also occur. Additional air pressure through upward movement of the larynx, as in ejectives, is obviously not possible for an open glottis gesture. Thus, with respect to phonological segmentation, a sequence like [taa] is ambiguous: PP analyzed it as a three-segment sequence /tha/; Steriade as a three-segment sequence underlyingly and a two-segment sequence on the surface; we analyze it as a plain onset and an aspirated nucleus /ta/. Our treatment of PP's [ChV] as $/ \mathrm{ta} /$ is analogous to [C?V] which is necessarily [ta]. Again, we find parallels in other Mazatecan dialects as well as other Otomanguean languages. ${ }^{5}$

According to our analysis, then, $[\mathrm{sg}]$ and $[\mathrm{cg}]$ are features of the nucleus in [ta] and [ta]. We have yet to explain, of course, why the entire nucleus is not breathy or creaky-voiced. We do so in terms of acoustic transparency (Silverman 1994). Mazatec nuclei carry a great deal of distinctive tonal information; since tone, [sg], and [cg] are all produced with the same articulator, the acoustic cues for tone are blurred in a completely breathy or a completely creaky nucleus. Acoustic transparency of the cues for tone and creaky or breathy voice is achieved by cutting off breathiness or creakiness midway into the vowel, allowing most of the tonal material to be produced in a modal setting. Similar strategies are found throughout Otomanguean languages, where laryngeal features in the nucleus may precede the vowel,

\footnotetext{
${ }^{5}$ See, e.g., Kirk, Ladefoged, and Ladefoged (1993) on Jalapa Mazatec, discussed below. Other Otomanguean languages with [CVhV] include Isthmus Zapotec (Pickett et al. 1959), Mixtec, Cuicatec, and Trique (Longacre 1957).
} 
interrupt, or follow it (see Rensch 1976 for details in the numerous daughter languages).

A similar functional account can be given for preaspiration and preglottalization in Huautla onsets. If aspirated and glottalized nuclei are realized as [aa] and [aa], aspirated and glottalized onsets must be realized in a manner that is acoustically distinct. Since postaspiration and postglottalization of an onset could also yield something very much like [aa] and [aa], phonetic implementation realizes laryngeal contrasts on onsets before closure, i.e., as preaspiration and preglottalization. Thus we see preaspiration and preglottalization in Mazatec as a phonetic strategy for maintaining a contrast between laryngealized onsets (consonants) and laryngealized nuclei (vowels), a contrast which runs the risk of neutralization if laryngealized onsets are realized with postaspiration or postglottalization.

To sum up, the phonetic evidence argues against the claim that postconsonantal aspiration and glottalization in Mazatec are part of the onset or part of the consonants that make up the onset. The fact that postconsonantal laryngeals are realized either on the vowel or immediately before it (but never on the preceding consonant) strongly suggests that the corresponding features are part of the nucleus.

2.2. Phonological evidence. PP postulate a large number of onsets for the language, given in table $1 .^{6}$ Our analysis does away with all of the bulleted $(\bullet)$ rows and the bulleted column. The bulleted glottal column is

${ }^{6}$ For the sake of simplicity we omit from general discussion [r] (which PP say is very rare), $[\tilde{r}]$ (which only occurs in Spanish loans), and three onsets composed of sibilant + stop which play little role in the discussion: [sk, $\left.\int \mathrm{t}, \int \mathrm{k}\right]$. Steriade treats the latter by complicating the notion of closure to include an Approach phase: [[Approach [Closure Proper]] Release] (1994:248). This greatly enriches aperture theory, obviously, but Steriade is silent on the consequences of the move. None of the sibilant + stop onsets is homorganic. This is interesting for two reasons. First, the occurring onsets seem to obey the feature co-occurrence restrictions on place features posited in (16) below. Second, sibilant + stop clusters in Huautla never contrast minimally with affricates, which ARE homorganic. Thus, ordering of sibilant and stop within a cluster is always predictable given the number of place specifications. We treat these onsets as follows:

$\begin{array}{ccc}\text { [sk] } & {[j \mathrm{t}]} & {[\mathrm{jk}]} \\ \mid & \mid & \mid \\ \text { cor } & \text { cor, front } & \text { cor, front } \\ \text { cont } & \text { cont } & \text { cont } \\ \text { dor } & \text { cor } & \text { dor } \\ \text { stop } & \text { stop } & \text { stop }\end{array}$

To avoid clusters like *[sl], *[sj], *[s $\left.\int\right]$, and so on, we need to invoke additional feature cooccurrence restrictions: $*$ [cont, son $]_{\text {Ons }}, *[\text { cont, cont }]_{\text {Ons }}$. None of this is relevant in deciding between our analysis or those of PP or Steriade. 
done away with by introducing breathy and creaky voice in the nucleus. This also removes the need for a contrast between $? C$ and $C$ ? or between $h C$ and $C h$, which eliminates almost half of the rows in table 1 .

Taking out the bulleted rows has other positive effects as well. As noted above, PP's account leaves us with two puzzling asymmetries. First, nasalization is distinctive for vowels $(a, \tilde{a})$ and for consonants $(t, n t)$, but aspiration and glottalization are distinctive only for consonants $(t, t h, t)$. We avoid this in our account because nasalization, aspiration, and glottalization are contrastive both for vowels (nuclei) and for consonants (onsets). Second, aspiration and glottalization are distinctive both pre- and postconsonantally according to PP, but nasalization is distinctive only preconsonantally $\left({ }^{*}\right.$ tna $)$. In our analysis postaspiration, postglottalization, and postnasalization of consonants do not occur, which eliminates the asymmetry; instead, we find contrastive aspiration, glottalization, and nasalization of nuclei, which fills in the apparent gap in (3), as discussed above. In general, Mazatec allows onsets and nuclei to be aspirated or not, glottalized or not, nasalized or not. In this way we avoid the asymmetries that plague PP's analysis as well as the need for postulating syllable constituents below the level of onset, nucleus, and coda.

Before turning to additional evidence for our analysis we would like to explain some of the gaps in Huautla's onset inventory (PP offer no discussion on this point; we return to gaps in the nucleus inventory below). Any adequate account of Huautla Mazatec must account for the systematic absence of onsets like [? $, \mathrm{h} f, ? \mathrm{l}, \mathrm{hl}, ? \mathrm{t}$, ?ts ... .]. We do so with feature cooccurrence restrictions against various types of onset: ${ }^{7}$

(10) Nasal-manner restrictions

No nasalized approximants

No nasalized fricatives

*[nas, approx]

(11) Laryngeal-manner restrictions

No aspirated or glottalized fricatives * $*$ LAR, cont]

No aspirated or glottalized laterals

*[LAR, lat $]$

(12) Laryngeal-nasal restriction

Glottalized onsets include sonorants $\quad[\mathrm{cg}] \rightarrow$ [son]

We use LAR in (11) as a cover feature for [spread glottis] and [constricted glottis]. The restriction in (12) precludes glottalized obstruents such as $*[t]$

\footnotetext{
${ }^{7}$ We do not treat restrictions on place-manner combinations (to account for the lack of onsets like $[\mathrm{p}],[\lambda]$, etc., in Huautla) here, as they do not play any role in the discussion. The restriction in (12) is admittedly ad hoc and requires further research; it goes unexplained by PP and Steriade as well.
} 
TABLE 1

Mazatec Onsets (Following Pike and Pike 1947)

\begin{tabular}{|c|c|c|c|c|c|c|c|}
\hline & Lab & & Cor & Pal & Ret & Dor & •Glott \\
\hline Stop, Affricate ${ }^{1}$ & & $t$ & $t s$ & $t \int$ & $t s$ & $k$ & $?$ \\
\hline preaspirated & & $h t$ & $h t s$ & $h t \int$ & $h t s$ & $h k$ & \\
\hline preaspirated prenasalized & & hnt & hnts & hntf & hnts & $h n k$ & \\
\hline preglottalized prenasalized & & $? n t$ & ?nts & ?ntf & $? n t s$ & $? n k$ & \\
\hline prenasalized & & $n t$ & $n t s$ & $n t \int$ & $n t s$ & $n k$ & \\
\hline - postaspirated & & th & $t s h$ & $t / h$ & $t s$ & $k h$ & \\
\hline - postaspirated prenasalized & & $n t h$ & $n t s h$ & $n t / h$ & $n t s h$ & $n k h$ & \\
\hline postglottalized & & $t^{?}$ & $t s^{?}$ & $t \int ?$ & $t s^{?}$ & $k ?$ & \\
\hline - postglottalized prenasalized & & $n t^{?}$ & $n t s ?$ & $n t f ?$ & $n t s^{?}$ & $n k ?$ & \\
\hline - preaspirated postglottalized & & hts? & & $h t ? ?$ & & & \\
\hline Fricative & & & $s$ & $\int$ & & & $h$ \\
\hline - postaspirated & & & $s$ & $\int h$ & & & \\
\hline - postglottalized & & & $s^{?}$ & & & & \\
\hline Nasal & $m$ & & $n$ & $n$ & & & \\
\hline preaspirated & $h m$ & & $h n$ & $h n$ & & & \\
\hline preglottalized & $9 m$ & & $7 n$ & $3 n$ & & & \\
\hline postaspirated & $m h$ & & $n h$ & & & & \\
\hline - postglottalized & $m ?$ & & $n ?$ & $n^{?}$ & & & \\
\hline Lateral & & & $l$ & & & & \\
\hline - postglottalized & & & $l 7$ & & & & \\
\hline Glide & $\beta$ & & & $j$ & & & \\
\hline preaspirated & $h \beta$ & & & $h j$ & & & \\
\hline preglottalized & $2 \beta$ & & & $? j$ & & & \\
\hline - postaspirated & $\beta h$ & & & & & & \\
\hline - postglottalized & $\beta ?$ & & & $j ?$ & & & \\
\hline
\end{tabular}

'Stops and affricates are lumped together here because their behavior is parallel with respect to laryngeal (and nasal) contrasts. Affricates fill missing stop contrasts but for one case: for the anterior coronals we do not know whether the contrast is also one of place (dental vs. alveolar, as we sometimes find in languages which also contrast two posterior coronals; see, e.g., Gnanadesikan 1993) or simply one of manner, affricates being strident stops as assumed by Steriade (1994). PP state that [ts] and $[\mathrm{n}]$ are alveolar but do not say whether [s] and [t] are alveolar or dental: we have treated the latter as dental to facilitate parallels with the rest of the phonology, but nothing in our analysis depends on this assumption. Note that /J/ is phonetically retroflexed before vowels according to PP.

and $*[\mathrm{~s}]$ but allows glottalized PRENASALIZED stops like $\left[{ }^{\mathrm{n}} \mathrm{t}\right]$ as well as glottalized nasals $[\mathrm{n}]$ and glides $[\beta]$ ].

We are now in a position to simplify our analysis of Huautla onsets. Given the feature co-occurrence restrictions in (10)-(12) and the otherwise free association of [sg], [cg], and [nas] to onsets, we may reduce the onset system of Huautla to the set given in table 2 . Note that we have omitted the column that contains [h] and [?]. This is because we treat $h$ - and ?-initial 
TABLE 2

MaZATEC OnSETS (REvised)

\begin{tabular}{|c|c|c|c|c|c|c|}
\hline & Lab & & Cor & $\mathrm{Pal}$ & Ret & Dor \\
\hline Stop & & $t$ & $t s$ & $t f$ & $t s$ & $k$ \\
\hline aspirated & & $t$ & $t s$ & $t / 2 \int$ & $\lfloor s$ & $\underline{k}$ \\
\hline aspirated nasalized & & ${ }^{n_{t}}$ & ${ }^{n} t s$ & ${ }^{n} t \int$ & ${ }^{n} t s$ & ${ }^{n} \underline{k}$ \\
\hline glottalized nasalized & & ${ }^{n} t$ & ${ }^{n} t s$ & ${ }^{n} t \int$ & ${ }^{n} \underline{\sim} s$ & ${ }^{n} k$ \\
\hline nasalized & & ${ }^{n} t$ & ${ }^{n} t s$ & ${ }^{n} t f$ & $n t s$ & ${ }^{n} k$ \\
\hline Fricative & & & $s$ & & & \\
\hline Nasal & $m$ & & $n$ & $n$ & & \\
\hline aspirated & $m$ & & $n$ & $n$ & & \\
\hline glottalized & $\stackrel{m}{\sim}$ & & $\underline{n}$ & $E^{2}$ & & \\
\hline Lateral & & & $l$ & & & \\
\hline Glide & $\beta$ & & & $j$ & & \\
\hline aspirated & $\beta$ & & & $j$ & & \\
\hline glottalized & $\underline{\sim}$ & & & $j$ & & \\
\hline
\end{tabular}

syllables like PP's $h a^{4}$ 'hawk' and $7 i^{4}-v i^{4}$ 'here' as containing aspirated and glottalized nuclei with empty onsets, in line with the rest of the analysis: $a^{4}$ 'hawk' and $i^{4}-v i^{4}$ 'here'. This follows from the restriction in (12), which bans inter alia onsets that consist solely of [h] and [?].

Further simplification is of course possible once segments are broken down into their constituent features, but this is not something we will pursue here. Our point is simply that we can treat glottalization, aspiration, and nasalization in Huautla as phonologically unordered features of onsets (consonants); extrinsic ordering of features within segments and extrinsic ordering of segments within onsets is not necessary.

Steriade (1994) makes the important observation that Mazatec avoids onsets like [?t?, hth, ?th, ht?], adducing this as evidence for a particular theory of what constitutes a segment (see below). We account for this pattern in another way, as a restriction on featural similarity between adjacent onsets and nuclei. For us, the gaps are of course $[\mathrm{t} V, \mathrm{tV}, \mathrm{tV}, \mathrm{tV})$. We propose that adjacent onsets and nuclei may not share certain features in Huautla. For the cases at hand, we propose a restriction against adjacent laryngeal specifications within a syllable:

(13) No tautosyllabic laryngeal features

$$
\text { * [LAR LAR }]_{\sigma}
$$

This constraint says that a syllable nucleus may only be aspirated or glottalized if its onset is not, and vice versa. We assume it is driven by the Obligatory Contour Principle, a restriction against adjacent identical phonological 
elements (Leben 1973 and McCarthy 1986; 1988). It rules out the cases in (14) and allows those in (15):

(14) Tautosyllabic laryngeal features

$$
* \text { [na }] *[\text { na }] * \text { [ta }] *[\text { ta }] \quad \text { etc. }
$$

(15) Single laryngeal features

[na $[$ ta $\quad[\mathrm{ta}] \quad[\mathrm{ta}] \quad[\mathrm{ta}]$ etc.

There is nothing ad hoc about the constraint in (13). As we shall now see, this type of constraint is widespread in Huautla Mazatec not only for laryngeal but also for supralaryngeal features.

PP note a number of "restrictions ... in the relationship between permitted margins and permitted vowels of the nuclei" (1947:87) which we may characterize as follows:

(16) Feature co-occurrence restrictions within the syllable * [labial labial $]_{\sigma}[0]$ is never preceded by $[\beta]$ or its clusters

[o] is very rarely preceded by $[\mathrm{m}]$

* [front front $]_{\sigma} \quad[\mathrm{e}]$ is never preceded by $\left[\int\right]$

$[\mathrm{e}]$ is very rarely preceded by [ts] or $\left[\mathrm{t} \int\right]$ or their clusters, nor by $[\mathrm{n}]$ or [j]

[i] is never preceded by [ $\mathrm{n}$ ] or its clusters

[i] is very rarely preceded by [ts] or its clusters, or by [j]

$*[\mathrm{sv} \mathrm{sv}]_{\sigma} \quad$ nasalized vowels are never preceded by $[\beta, \mathrm{j}, 1, \mathrm{r}]$ or their clusters, nor by [m, n, n]

(The full set of vowels assumed by PP is given below in table 3.) The first of these restrictions is perhaps the clearest, since $[\mathrm{o}, \beta, \mathrm{m}]$ are all sounds made with the lips. The second requires that $\left.\left[e, i, \int, t s, t\right\}, n, j\right]$ share a feature, which we take to be [front] following Pulleyblank (1989), Keating and Lahiri (1993), Hall (1995), and others. ${ }^{8}$ The third requires that nasalized vowels and sonorant consonants share some feature-following Rice (1993) we assume that this feature is [sonorant voice].

In our account, then, syllables that would have been transcribed by PP as [?C?V] [hChV], [?ChV], and [hC?V] are systematically banned by the same mechanism that bans *[nã], *[ßo], and *[ ni]. Thus, although Huautla uses nasalization, aspiration, and glottalization contrastively in both onsets and

\footnotetext{
${ }^{8}$ It should be noted that our analysis is also compatible with other accounts treating palatals and front vowels as (posterior) coronals (e.g., Hume 1992). We do not yet understand why retroflex [ts] patterns with these sounds. We leave this for future research as it does not help decide between competing accounts of Huautla; neither PP nor Steriade offers any account of the facts in (16).
} 
rhymes, it places strict restrictions on adjacent instances of these and a good many other features within a syllable.

3. Nuclei. There is phonetic and phonological support for the claim, then, that "postaspiration" and "postglottalization" are features of nuclei rather than onsets. In this regard we find it very significant that the same phonation contrasts we have posited for Huautla occur in a closely related dialect of Mazatec, Jalapa (Kirk, Ladefoged, and Ladefoged 1993). Kirk, Ladefoged, and Ladefoged transcribe the contrasts as follows:

$$
\begin{aligned}
& \text { Creaky } \\
& j \underset{a}{a} \text { 'he carries' (cf. Huautla } j a^{3} a^{3} \text { 'I carry' [PP 1947:81]) } \\
& \text { 'arse' }
\end{aligned}
$$

(18) Breathy

ja 'he wears'

ndæé 'horse'

(19) Modal

$\begin{array}{lll}j a ́ & \text { 'tree' } & \text { (cf. Huautla ja } a^{l} \text { 'wood' [PP 1947:88]) } \\ n t^{h} \mathfrak{a ́}^{\prime} & \text { 'seed' } & \end{array}$

As in Huautla, creaky voice in Jalapa is not realized uniformly throughout the vowel but trails off. This is clearly seen in wide-band spectrograms of five speakers for both creaky and breathy voice (reprinted in Ladefoged and Maddieson 1996 as well): "For all speakers, breathy voice is more clearly seen in the onset part of the vowel since the coda section of the vowel tends to have modal voice.... For all speakers, the pattern is for [creaky glottal] pulses to be grouped closer together at the onset of the vowel followed by increased distances between pulses moving toward the center of the vowel, followed by decreased distances between pulses toward the coda of the vowel" (Kirk, Ladefoged, and Ladefoged 1993:442). This matches PP's description of postglottalization and postaspiration in Huautla (see above) almost exactly. There is little point in treating the same phonetic facts as vowel-based in Jalapa and as consonant-based in Huautla and we therefore analyze both as vowel-based.

Turning now to vowel quality, PP propose for Huautla the four vowels and nine diphthongs shown in table 3 (contrastive nasalization excluded for simplicity; our analysis does away with bulleted rows). ${ }^{9}$ What appear to be

\footnotetext{
${ }^{9} \mathrm{PP}$ give the following phonetic description of their vowel phonemes: "The vowel $a$ varies freely toward $[\Lambda] ; e$ tends to be phonetically $[\varepsilon] ; i$ has no prominent variants; $o$ varies freely over a considerable range from [o] to [u]" (1947:83). We follow PP's transcriptions here to avoid confusion, but note that $/ \mathrm{u} /$ rather than $/ \mathrm{o} / \mathrm{seems}$ to be the better choice for the back rounded vowel (Paul Kirk, personal communication).
} 
TABLE 3

Mazatec Nuclei (Pike and Pike 1947)

\begin{tabular}{lcccc}
\hline \hline Monophthong & $a$ & $e$ & $i$ & $o$ \\
- $a$-Diphthong & & $a e$ & $a i$ & $a o$ \\
- $i$-Diphthong & ia & ie & & io \\
- $o$-Diphthong & oa & oe & oi & \\
\hline
\end{tabular}

contrasting vowel sequences, [oa] vs. [ao], etc., constitute PP's evidence for complex nuclei. At first blush the data support their argument straightforwardly. Examples of (near) minimal pairs include the following (using PP's transcription):

(20) Contrasting "diphthongs" in Huautla chao ${ }^{42}$ 'egg' c?oa ${ }^{3}$ 'his mouth' $n ? \tilde{a} \tilde{\imath}^{42}$ 'father' $n t ? i a^{34}$ 'house'

PP conclude on the basis of such contrasts that Huautla has the four vowels and nine sequences shown in table 3 . Besides one systematic and rather surprising gap $(* e a, * e i, * e o)$, all combinations of vowels seem to be attested as diphthongs. PP take this as evidence that nuclei are internally complex and right-headed, basing the right-headedness claim on two considerations. First, all vowels are allowed as the rightmost member of a sequence but only $[a, i, o]$ are allowed as the leftmost. Second, the duration of the rightmost vowel is much greater than the duration of the leftmost vowel: "usually the second [vowel] is phonetically more prominent, since in the rapid pronunciation of the two-vowel nucleus the first tends to be reduced very sharply while the second remains the stronger and seems to carry the large share of the tonal glide if one is present" (1947:83).

One final detail: all nuclei, complex or simple, are of the same duration-[a] and [ai] and [ao] are equally long and there is no contrast between long and short vowels or between long and short diphthongs: "Two vowels juxtaposed ... do not make two syllables; the two vowels are pronounced together very rapidly, so that the timing seems to be about the same as that for a single vowel. The nucleus of the syllable takes about the same length of time-within the limits of perception-regardless of the number of vowels it contains, whether one or two or three" (1947:78-79). (Three-vowel syllables only occur in morphologically complex words, like three-toned syllables; we shall not consider them here as they pose no difficulty for our analysis or for PP's.)

We analyze the allegedly nucleic phenomena of Huautla in much the same way as we analyze the onset phenomena, by partitioning the vocalic 
features into onsets (as glides) and nuclei (as vowels). We shall see that this explains the missing $* e o, * e a, * e i$ diphthongs as well as the durational asymmetry between the first and the second vowel in a vowel sequence. We suggest that the following transcriptions more accurately reflect the phonological reality of Huautla than those in (20):

\begin{tabular}{|c|c|c|}
\hline & 'egg' & $c^{w} \underline{a}^{3}$ \\
\hline$n^{n u} \tilde{u}^{42}$ & 'father' & $n t^{j} \underline{a}^{34}$ \\
\hline
\end{tabular}

That is, we treat the initial vowel in a two-vowel sequence as a glide in the preceding onset. The glides in question are labial [w], coronal [j], and dorsal [u] ${ }^{10}$ We explain the lack of *[eo, ea, ei] diphthongs by the lack of a plausible way of making [e] into a glide distinct from [j]. We know of only four simple ways of modifying an onset with vowel-like features: labial $(w)$, coronal (j), dorsal (ul), and pharyngeal ( $($ ). As it makes no distinctive use of pharyngealization, Huautla is limited to three secondary articulations on onsets, [w], [j], and [u] . The length of the second of two vowels follows as well since glides are inherently shorter than vowels.

In this analysis, Huautla nuclei contain a simple short vowel $(a, e, i, o)$ with or without tone, nasality, breathy voice, or creaky voice. Again, we posit the same set of associational possibilities for onsets $(w, j, u)$ as we do for nuclei $(o, i, a)$ except that front [e] and [i] are neutralized in the onset as $[\mathrm{j}]$ and tones are allowed only in the nucleus. This complicates the set of possible onsets in Huautla, of course, but in a principled way, by allowing

\footnotetext{
${ }^{10} \mathrm{PP}$ consider and reject the possibility that prevocalic [a] is a glide: " $a$ is certainly vocalic in $a i$ and $a o$, though it is less prominent than the $i$ and the $o$, SINCE THERE IS NO CONSONANT WITH WHICH IT CAN BE CONFUSED" (1947:85 [emphasis ours]). Pattern analogy then forces them to treat prevocalic [i] and [o] as vowels as well: "Once vowels such as the $a$ are found to carry but little prominence while preceding another vowel, the pattern allows both $i$ and $o$ in $i a$ and $o a$ to be vocalic even though they also have little prominence and precede another vowel. In other words, assuming $a$ to be always vocalic, even when the first of a cluster of two vowels, the pattern pressure on $o$ and $i$ can be expressed in a proportionate formula ..." (1947:85). We reject the claim that there is no glide that corresponds to a low back vowel: the standard IPA symbol for such a sound is [u् ]. Articulatorily, [i] and [i] differ only with respect to stricture, as do [u] and [w]. Strengthening of low back vowels to [u् ] results in increased stricture between the lower tongue body or tongue root and the uvula or pharyngeal wall.

Phonological evidence for such a relationship is not hard to come by: a velar glide may occur between two low back vowels in Axininca Campa (Black 1991 and Spring 1992). It is claimed to be the source of "intrusive $r$ formation" in nonrhotic English dialects by Broadbent (1991) and the result of $R$-vocalization in German dialects (Hall 1993). We use [u] for velarization on an onset but leave open the possibility that the glide may be realized with some pharyngeal constriction. Ladefoged and Maddieson (1996:323) report a similar confusion in Danish: "the Danish ' $r$ ' sound in words such as 'raad' (council) is not a uvular approximant as some textbooks (Bredsdorf 1958) describe it, but a pharyngeal approximant with an articulatory position similar to that in a low back vowel."
} 
[labial, coronal, dorsal] as secondary articulations $(w, j, w$, respectively) on onsets alongside [cg], [sg], and [nas]. Our analysis makes maximal use of the distinction between nucleus and onset and posits no extrinsic ordering of features or segments.

4. Previous analyses. Both analyses we consider here are based on the same assumption, that postconsonantal laryngeals in Huautla are part of the onset rather than part of the nucleus, an assumption we hope to have cast doubt upon. In this section we would like to look more closely at the consequences of assuming that onsets (PP) or segments (Steriade) may be contrastively pre- or postlaryngealized.

4.1. Pike and Pike (1947). As we have seen, PP propose that onsets $(h / t, t / h)$ and nuclei $(a / o, o / a)$ are complex in Huautla and that segments may be distinctively ordered within these subsyllabic constituents. We see four areas in which this proposal is problematic:

Prosody. PP's analysis requires nasal and laryngeal segments to occur as satellites either to the left or to the right of the onset head: $(h / t)$ vs. $(t / h)$. We have shown that this theoretical richness is not forced by the data because a simpler analysis is available which does not require it: there is no need to contrast [ht] and [th] in Huautla. Prelaryngealized and prenasalized onsets may be analyzed simply as onsets with the features [sg], [cg], and [nas]. This avoids a conceptual problem inherent in PP's treatment of onsets that consist solely of [h] or [?] or [n]: if these segments are "satellites," why can they occur in isolation?

Turning now to the prosody of the nucleus, we note that PP's analysis fails to account for the systematic gap * [ei, ea, eo], a surprising gap given that all other vowel-vowel combinations are attested. It also must stipulate that all diphthongs are realized iambically regardless of the sonority of each member (ia, aii), an odd restriction at best; and it requires subnucleic constituent structure to work at all. Our analysis suffers from none of these shortcomings.

Markedness. According to PP's analysis, Huautla violates the sonority sequencing principle (Sievers 1881 and Jespersen 1904) in a fundamental way: for most languages, if two sounds are allowed in the onset, their relative order is fixed. But given PP's analysis the order of [h] and [?] with respect to other consonants in the onset is contrastive and not subject to general phonotactics. While such a situation is not necessarily impossible (the sonority sequencing principle need not be inviolate), it should give us pause. We have shown that an adequate account of the data is possible that does not require this marked situation. 
Similar considerations hold for the nucleus. Languages with contrastively rising and falling diphthongs ( $a o$ vs. $o a$ ) are quite rare and often amenable to reanalysis along the same lines we have offered here. Languages with contrastive phonation on vowels, on the other hand, are well known: Gujarati contrasts modal and breathy vowels (Pandit 1957); Mpi contrasts modal and laryngealized vowels (Ladefoged and Maddieson 1996:315-17). Three-way contrasts are found in Jalapa Mazatec, as we have seen, and !Xóõ makes a four-way contrast with plain, pharyngealized, strident, and breathy vowels (Traill 1985).

Symmetry. The appeal of PP's analysis is surely its overall symmetry: the (apparent) [th] vs. [ht] distinction and (apparent) [ao] vs. [oa] distinction are both handled in terms of complex subsyllabic constituents. But the symmetry breaks down. First, aspiration and glottalization are allowed in two places in the onset but nowhere in the nucleus. Second, there is the gap in (3): postaspiration and postglottalization are allowed alongside preaspiration and preglottalization [ht, th; $\mathrm{hm}, \mathrm{mh}$ ] but postnasalization is not found alongside prenasalization [nt, *tn]. Finally, there is a gap in PP's system of onsets (table 1): postaspiration, postglottalization, and preaspiration are all allowed on oral stops but preglottalization is not $(* \eta t, *\urcorner k)$.

Our analysis is more symmetrical in this respect and more constrained as well. First, aspiration, glottalization, and nasalization are allowed only once in the onset and once in the nucleus. Second, the gap in (3) is done away with by treating "postaspiration" and "postglottalization" as the laryngeal analogues of nasalized vowels. Finally, there is the anomalous lack of preglottalized stops: they constitute another gap in the inventory of Huautla onsets. This gap disappears along with preglottalized and postglottalized obstruents: the generalization emerges that only onsets with sonorants in them can be glottalized. In our analysis Mazatec allows almost all features to be realized distinctively on onsets (consonants) or on nuclei (vowels) but requires no extrinsic ordering of features ${ }^{11}$ within onset or nucleus, making maximal use of minimal resources.

Phonetics. We have already seen that the phenomenon of glottally interrupted vowels speaks for glottalization of the nucleus rather than postglottalization of the onset. Here we look at a different phonetic consideration: how the phonological analyses can be translated into the actual phonetic forms in a natural way. Because PP posit sequences of ordered segments for what we call nasalization, aspiration, and glottalization, preaspirated and preglottalized stops are the natural outcome of their $/ \mathrm{hC} /$ and $/ 7 \mathrm{C} /$

\footnotetext{
${ }^{11}$ Except for the tonal features, of course.
} 
forms. In other cases, though, there is considerable overlap of oral, nasal, and laryngeal gestures. Sequences of $/ \mathrm{n}+\mathrm{stop} /$, for instance, are realized as homorganic and $/ \mathrm{h}+$ sonorant/ sequences are realized as partially breathy sonorants ([mm]). Both cases require rules of assimilation: "alveolar $\mathrm{n}$ becomes velar before velar stops" and "the phoneme $\mathrm{h}$... before nasals ... becomes a voiceless nasal fricative" (1947:80).

For us, the difficulty is reversed: nasalization, aspiration, and glottalization are simply features of onsets or nuclei rather than extrinsically ordered segments. Thus, they do not involve any supralaryngeal place specifications on their own and should overlap with the supralaryngeal articulations in onsets and nuclei. What we must account for, then, is the phonetic ordering of laryngeal and supralaryngeal gestures. According to our analysis, the main difference between Huautla and most other languages is that the former PREPOSES its laryngeal gestures to maintain the phonological contrast with laryngeal specifications in nuclei. Most other languages POSTPOSE laryngeal gestures so that they occur during the release of consonants in the onset (Kingston 1990).

Our featural account is superior to PP's segmental analysis because a simple phonetic strategy can account for the different gestural timings: features are phonologically attached to onsets (consonants) or nuclei (vowels) but may be ordered phonetically with respect to things like closure in order to remain audible and distinct.

4.2. Steriade (1993; 1994). Steriade's analysis differs from PP's and from ours in a numbers of ways, not all of them relevant to the present discussion. The heart of the proposal is that plosives (stops and fricatives) are phonologically complex and consist of a closure $\left(\mathrm{A}_{0}\right)$ and a release phase $\left(A_{\max }\right)$ : this phonological complexity allows plosives to be distinctively pre- vs. postaspirated, pre- vs. postglottalized, and pre- vs. postnasalized (on the surface if not underlyingly). Other speech sounds (fricatives, glides, liquids, and vowels) have only a single aperture phase and are simply aspirated, glottalized, or nasalized: no pre- vs. postdistinctions are possible. This is sketched briefly below, where vertical lines show the phase $\left(\mathrm{A}_{0}, \mathrm{~A}_{\max }\right.$, or $A_{f}$ for fricatives) during which the glottis is constricted or spread (for fuller discussion, the interested reader is referred to the original articles).

(22) Aperture theory

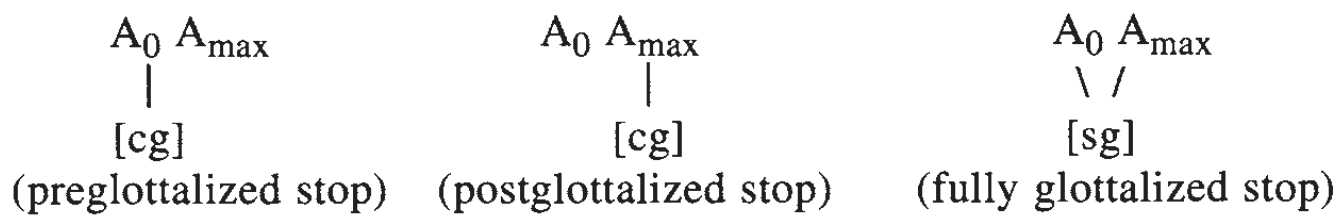




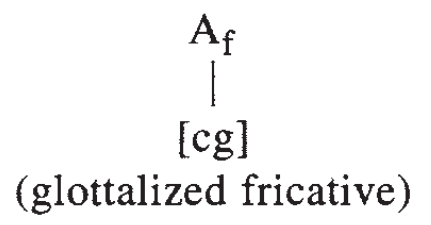

$\mathrm{I}_{\max }^{\mathrm{cg}]}$

(glottalized glide)

We focus here on four issues pertaining to Steriade's analysis of Huautla: markedness, plosives, vowels, and abstractness. Our general claim is that aperture theory is too rich because it allows for contrasts (pre- vs. postlaryngealized consonants) that do not occur in natural language.

Markedness. In her 1994 article Steriade notes that aperture theory easily accommodates her analysis of Huautla: "The suggestion made here is that onset systems like [Huautla's] are governed by the same organizing principles as standard onset inventories of the type \{ single $\mathrm{C}$; or $\mathrm{pr}, \mathrm{tr}, \mathrm{kr}$, $\mathrm{pl}, \mathrm{kl}$ \}. If anything, the more unusual cluster set in [Huautla] will emerge as better, i.e., structurally closer to the optimal single $\mathrm{C}$ onset, than the standard collection of obstruent-liquid clusters" (1994:204). The analysis therefore cannot account for the EXCEPTIONALITY of Huautla, either with respect to other Mazateco-Popolocan languages or with respect to languages generally. If systems like Huautla's are better than obstruent-liquid clusters, we cannot explain why (putative) systems of this sort are so rare cross-linguistically. Steriade herself notes that "all the dialects of Mazateco-Popolocan I have encountered differ from Huautla in lacking a widespread and systematic contrast between pre- and postaspirated or pre- and postglottalized onsets" (1994:258).

Huautla does not have a widespread and systematic contrast between preand postaspirated or pre- and postglottalized onsets either. This fits what we know outside of Popolocan languages: phonological contrasts of preand postaspirated plosives do not occur in the languages of the world as far as we can tell. Preaspiration, which we have reanalyzed out of Mazatec phonology, is a case in point: "Despite its importance in specifying the phonetic characteristics of some languages, we do not know of any language in which it is necessary to regard preaspiration as a feature required for distinguishing underlying forms" (Ladefoged and Maddieson 1996:73). Similarly for pre- and postglottalized plosives, pre- and postnasalized plosives and, we suspect, for pre- and post-anythinged plosives.

Our analysis posits no exotic structures or contrasts for Huautla. We do assume that most features can be contrastively associated with nuclei (vowels) or onsets (consonants) but this is completely uncontroversial: aspiration, glottalization, and nasalization of onsets are well attested in the languages of the world, as are breathy voice, creaky voice, and nasalization of nuclei.

Plosives. We have argued against the claim that Huautla contrasts pre- and postglottalized or pre- and postaspirated consonants of any kind, 
plosives or otherwise. There is thus no need to postulate a special phonological representation for Huautla plosives because they show the same type of contrast (having a feature or not) as all other classes of speech sound. Consider the systematic gaps described in (10)-(12), repeated below for convenience:

(23) Nasal-manner restrictions

No nasalized approximants

No nasalized fricatives

*[nas, approx $]$

$*$ [nas, cont]

(24) Laryngeal-manner restrictions

No aspirated or glottalized fricatives * [LAR, cont]

No aspirated or glottalized laterals

$$
\text { *[LAR, lat }]
$$

(25) Laryngeal-nasal restriction

Glottalized onsets include sonorants $\quad[\mathrm{cg}] \rightarrow[$ son]

Once postaspiration and postglottalization are taken out of the picture there is not a single generalization about aspiration, glottalization, or nasalization in Huautla that makes reference to plosives. Huautla does not treat plosives in a special way and does not treat them as a phonological class.

Steriade argues of course that plosives Do form a natural class in Huautla, with respect to preglottalization and preaspiration. Let us examine these claims more closely. Steriade claims that "preglottalization is permitted with plosives only: there are no /?s/, /7J/, /71/, /?r/ clusters in Mazateco" $(1994: 240) .{ }^{12}$ But she immediately goes on to note that "the closure of a preglottalized stop must be nasal." The simplest generalization here is that preglottalization can only occur with (nonliquid) sonorants; the class of plosives plays no role here because some of them (nasals and prenasalized stops) license preglottalization while others (oral stops and affricates) do not.

Steriade also claims that "all and only plosives and plosive clusters can be preaspirated"; but this assertion is true neither of her underlying nor of her surface representations. On the surface Huautla has preaspirated $[\mathrm{h} \beta]$ and [hj] as well as a large number of preaspirated plosives. Steriade handles the first case by claiming that $[\beta]$ is a labial stop underlyingly (1994:219), a claim for which there is little justification; ${ }^{13}$ she handles the

\footnotetext{
${ }^{12}$ There are two surface exceptions to this: a preglottalized palatal glide [ $\left.2 \mathrm{j}\right]$ and a preglottalized voiced labial fricative [? $?$ ]. Steriade treats the first as an underlying [?i], the second as an underlying [?p] or [?b]. The latter would seem to conflict with her claim that the closure of a preglottalized stop must be nasal.

${ }^{13}$ Steriade argues for underlying [b] on the basis of markedness: "This $[\beta]$ occupies an odd position in the Mazateco consonant system: it is the only voiced fricative of a language in which an oral bilabial stop is strikingly absent. Very few languages lack a bilabial oral stop; and relatively few have, in their phonemic inventories, voiced bilabial fricatives ..."(1994:219). But
} 
second case by claiming that [hj] is really [hi] underlyingly and thus poses no threat to her generalization. ${ }^{14}$ The analysis is incoherent because the statement that "all and only plosives and plosive clusters can be aspirated" is true neither underlyingly nor on the surface. Underlyingly THERE ARE NO preaspirated plosives or plosive clusters ("all complex onsets in Mazateco are underlying clusters" [1994:222]) and on the surface there are preaspirated sounds that are not plosives ([hj], [h $\beta])$. The simplest generalization for Huautla is that fricatives and laterals cannot be aspirated; the natural class of plosives (if it is one) plays no role here.

Similar considerations obtain for other languages that Steriade discusses. Plosives seem to play an important role in her analysis of Chiquihuitlan Mazatec, but this is because she often uses the term "plosive" to refer to cases where only oral stops are meant (1994:269-71). Her "plosive $+h$ " cases include aspirated oral stops but no aspirated nasal stops and her " $n+$ plosive" cases include prenasalized stops but not, of course, prenasalized nasals. Once we use the proper term (oral stop in both cases) we see that these patterns have nothing to do with plosives. The only place where plosives seem to behave as a class in Chiquihuitlan is in the existence of the clusters " $s+$ plosive," " $f+$ plosive," and (possibly) " $r+$ plosive." But in precisely these cases aperture theory plays no role in Steriade's analysis: Steriade treats these types of onsets as segmentally complex, with the result that aperture theory cannot explain why $\left[s, \int, r\right]$ occur only with plosives.

Steriade claims that Yuchi contrasts pre- and postglottalized stops, citing a brief article by Wolff (1948) but no minimal pairs or detailed distributional statements. More thorough analyses of Yuchi phonology (Wagner 1931; 1934, Crawford 1973, and Ballard 1975), however, do not have this contrast between pre- and postglottalized stops and we know of no data

lacking a labial stop is the most common pattern for Popolocan languages: labial stops never surface in Huautla or in any other dialect of Mazatec; they do not occur in any other Popolocan language (except in loans) and are not reconstructed for Proto-Popolocan (Gudschinsky 1953 ; 1959) or even for Proto-Otomanguean (Rensch 1976:12ff.). Their absence is a completely stable phenomenon in Popolocan languages and does not require a rule of complete neutralization to account for it. Maddieson (1984:34-37) devotes a few pages to the discussion of "missing p" (and "missing g") in the inventories of many Afro-Asiatic, Nilo-Saharan, and New Guinean languages. For these reasons, we follow standard practice in treating Mazatec $[\beta]$ as a labial glide (see Rensch 1976 and references therein).

${ }^{14}$ Again, there is no synchronic evidence for the complete neutralization she proposes and comparative evidence shows that syllable-initial glides have been and continue to be a stable part of Popolocan languages and of Otomanguean languages generally (Rensch 1976). Here again we follow standard practice and treat $[\mathrm{j}]$ as a palatal glide. There is another problem with $[\mathrm{j}]$ being underlying /i/: as shown in table 1 , both $/ 2 \mathrm{j} /$ and $/ \mathrm{j} / /$ are attested in PP's or Steriade's analysis; but it is not clear how $/ \mathrm{i}$ ?V/ can be realized under Steriade's analysis, where laryngeals never attach to vowels. A form like /i?a/ should surface as heterosyllabic [i.?a] (since laryngeals do not attach to vowels) but in fact shows up as monosyllabic [ja]. 
that support it. (Wolff does not offer any evidence for the alleged contrast and does not discuss Wagner's earlier analysis, which does without it.) There is some disagreement over whether Yuchi has glottalized consonants (Rensch 1976:304 and Crawford 1973:174) or simply clusters of glottal stop + consonant (Ballard 1975:164); but there is no hint of a contrast between pre- vs. postglottalized consonants in any detailed treatment of the language. Wagner (1934:300) claims that Yuchi actually has a series of glottalized vowels, an analysis to which we are very partial. His analysis of Yuchi is like our analysis of Huautla: the language contrasts glottalized and nonglottalized consonants as well as glottalized and nonglottalized vowels. In any case, there is no evidence for aperture theory in Yuchi once one gets past the superficial sketch in Wolff (1948) because there is no evidence for a contrast between pre- and postglottalized consonants in the language. ${ }^{15}$

The final language Steriade discusses in her 1994 article is Kashaya, focusing on Buckley's $(1990 ; 1992)$ analysis of laryngeal increments. A full discussion of the facts lies beyond the scope of this paper but we may note here that Kashaya has no surface contrast between pre- and postlaryngealized onset consonants and thus makes a rather weak case for aperture theory. "Incremental" morphemes like - $>k^{\prime} o l^{h}$ - 'spill' surface with the initial laryngeal in the coda of the PRECEDING syllable; the only evidence that clusters like $7 k ?$ are (ever) tautosyllabic comes from a reduplication process which copies the whole cluster. Steriade takes this as evidence that such clusters are (at the relevant stage in the derivation) monosegmental, but nothing forces this conclusion. Buckley's own proposal uses moras (not segments) to license laryngeal increments. For a detailed critique of Steriade's analysis of Kashaya, we refer the reader to Buckley (1993) who argues that aperture theory is neither necessary nor helpful in analyzing Kashaya incrementals. ${ }^{16}$

\footnotetext{
ing to anyone's analysis). ejectives as follows:
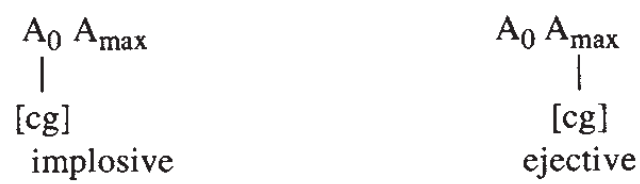

${ }^{15}$ In his 1931 work Wagner claims that the "vowels as well as the consonants ... occur aspirated and glottalized" (1931:ix). In his 1934 grammatical sketch he treats aspirated vowels as [hV] sequences but does not explain his change of heart. The point is irrelevant to the discussion at hand because there is no contrast in Yuchi between pre- and postaspiration (accord-

${ }^{16}$ We note here one final problem with Steriade's analysis which Buckley does not discuss. Elsewhere in her work on aperture theory (1993:74ff.), Steriade characterizes implosives and

These representations are identical to the SURFACE representations proposed for pre- and postglottalized stops in Steriade (1994). We thus expect Huautla preglottalized clusters like [?nt] to 
In short, the languages that Steriade $(1993 ; 1994)$ discusses provide little support for aperture theory. Broadening the picture somewhat, we see that plosives do not behave as a uniform class in general. Generally, it is oral stops that show the greatest possibilities for contrast; nasal stops fall somewhere in between other sonorants and oral stops in this regard. For instance, we find only oral ejectives and implosives: sonorants, including the sonorant plosives, pattern alike here against oral stops (cf. Greenberg 1970). Similarly, aspiration with oral stops is always ordered with respect to closure: the peak of glottal opening either precedes or follows the closure phase, resulting in (phonetic) pre- and postaspiration; for sonorants, on the other hand, glottal opening tends to fall within the sound. All of this seems to indicate that it is not so much having a release which makes sounds special but rather the complete prevention of airflow during closure: distinctive laryngeal contrasts must be phonetically realized either before or after oral stop closure or else be masked. These facts would seem to support a distinction AMONG plosives (stops vs. nasals) at least as much as they support a distinction between plosives and other sounds.

Vowels. Steriade does not offer an analysis of vowels in Huautla, but it is nonetheless worth asking how this can be done within her system. We focus here on the phenomenon of laryngeally interrupted vowels. As we have seen, Huautla often realizes glottalization wITHIN the nucleus (CV?V, monosyllabic). Analyses such as Steriade's or PP's, which treat such glottalization as part of the preceding consonants or onset, must get the glottal pulse to surface within the following vowel. Steriade offers no rule to do this, nor any insights as to how such a rule might be formulated. We believe that any such rule is likely to be hard to formulate and ever harder to defend: there is no reason to analyze a laryngeally interrupted vowel as a modal vowel preceded by a glottal consonant.

Indeed, when Steriade analyzes similar facts in Western Popolocan she claims that "all sequences transcribed as /C?/ . . have glottalization associated not to the onset but to the following nucleus" (1994:262). Her evidence for this is $(i)$ that there is a lag between stop release and /?/, (ii) that vowels may be prearticulated before the $/ 7 /$, and (iii) that postglottalized consonant clusters induce a tonal shift in nuclei with tonal contours (1994:262). As we have seen, the first two facts are found in PP's description of Huautla

be phonetically implosive (they are not) and postglottalized clusters like [t?] to be phonetically ejective (they are not). It would seem that aperture theory cannot give distinct surface representations for preglottalized and implosive sounds or for postglottalized and ejective sounds. Note that whether preglottalized and implosive sounds or postglottalized and ejective sounds contrast in any language is irrelevant here; at issue here are surface representations, not underlying ones. 
as well, though Steriade does not there take them as evidence that the glottal feature is associated to the vowel.

Steriade proposes nucleus-based glottalization analyses for every Popolocan language she discusses EXCEPT Huautla Mazatec. This includes Western Popoloca, Tlacoyalco Popoloca (Stark and Machin 1977), Choapan Zapotec (Lyman and Lyman 1977), Guelavila Zapotec (Jones and Knudson 1977), and Chiquihuitlan Mazatec (Jamieson 1977a; 1977b). Her analysis of Chiquihuitlan, for instance, is essentially the same as Kirk, Ladefoged, and Ladefoged's (1993) analysis of Jalapa or our analysis of Huautla, with contrasting modal, breathy, and creaky voice on the nucleus:

Chiquihuitlan syllables are open. Nuclei may contain distinctive aspiration or glottalization, indicated orthographically by Jamieson as syllable-final $/ \mathrm{h} /$ and /?/: thus /sui?/ 'holiday' represents a glottalized nucleus, /ntoh/ 'soap' an aspirated one. In monovocalic nuclei the aspiration or glottalization is realized in the center of the vowel and perceived as an interruption in the vocalic gestures [VhV], [V?V].... Vowel glottalization and onset preglottalization contrast. . . (1994:269-70)

Jamieson's phonetic description of Chiquihuitlan phonation types is very similar to PP's description of postaspiration and postglottalization in Huautla and to Kirk, Ladefoged, and Ladefoged's description of breathy and creaky voice in Jalapa. ${ }^{17}$ We agree fully with Steriade's analysis of Chiquihuitlan; what we do not see is any significant difference between Huautla on the one hand and Jalapa and Chiquihuitlan on the other which keeps us from analyzing all three dialects with breathy and creaky voice vowels. All of them have a three-way phonation contrast between modal, breathy, and creaky voice; none of them has nasalized fricatives or sonorants (10), laryngealized fricatives or laterals (11), or glottalized obstruents (12); and none of them has a pre- vs. postcontrast in any distinctive feature.

Given the possibility of vowel-based analyses for all other Popolocan languages, there is no need for Steriade's consonant-based analysis of Huautla: aperture theory is not necessary for any Popolocan language.

Abstractness. Steriade analyzes Mazatec onsets as underlying segment clusters that are merged into single surface segments by rule:

The analysis I will propose claims that all complex onsets in Mazateco are underlying clusters: they originate as underlying sequences of distinct feature matrices linked to distinct A positions. However, in the process of onset formation, these clusters merge into structures that correspond to single seg-

\footnotetext{
${ }^{17}$ We note that Chiquihuitlan forms transcribed by Jamieson as [CVh] and [CV?] appear in Huautla forms transcribed by $\mathrm{PP}$ as $[\mathrm{ChV}]$ and $[\mathrm{C} ? \mathrm{~V}]$, respectively: Chiquihuitlan $c \varepsilon^{7314}$ vs. Huautla $c^{7} e^{2}$ 'lazy'. Again, this strongly suggests that the glottalization is phonologically part of the nucleus. Dialects differ as to where they realize the glottal pulse: toward the end of the nucleus in Chiquihuitlan and toward the beginning in Huautla and Jalapa.
} 
ments. Thus, /ht/ and /th/ are both segment sequences underlyingly. That is why they can be lexically distinct. But they are both monosegmental on the surface: one a preaspirated, the other a postaspirated stop. . . (1994:222)

These underlying clusters can surface as single segments because they contain no contours other than the aperture contours identical to plosive structure (i.e, $A_{0} A_{\max }$ or $A_{0} A_{f}$ for affricates). Specifically, a single segment cannot contain both [sg] and [cg] because they cannot be realized simultaneously (1994:216). Place contours are also banned because a monosegment "contains at most one place node" (1994:217). ${ }^{18}$

Our analysis is clearly simpler than the one proposed by Steriade in that it does not need any kind of merger rule. This is good because there is no evidence for the merger rule in Huautla-no synchronic alternations, no diachronic or comparative considerations support the claim that what PP transcribed as [?C], [C?], [hC], or [Ch] begin as clusters and end as single segments. Steriade claims that merger is required to allow such words to contrast but this is not the case: all that is required is a contrast between laryngealized onsets (consonants) and laryngealized nuclei (vowels).

There are two other rules in Steriade's account that should be mentioned here, neither of which is needed in our analysis. First, according to PP, Huautla has two rather marginal onsets, [hts?] and [ht f?], ${ }^{19}$ which are "rare and tend to vary to /ts?/ and /t $\mathrm{f}$ / " (1947:82). According to Steriade's principles of derived segmenthood, these cases have to be clusters on any derivational tier. Her solution to this problem is to analyze [hts?] and [ht ?] as underlying /sts?/ and /st $\int ? /$, respectively, derived by debuccalization of the initial spirant. We do not see any evidence for such a process (synchronic alternations, diachronic changes, etc.) and note that it does not avoid the problem in any case. The issue for Steriade is what makes a viable surface segment, not what makes a viable segment underlyingly: [hts?] and [ht ??] are bad surface segments according to Steriade's analysis, regardless of their derivational history.

There is another reason not to accept the debuccalization analysis. Consider the following: "Another gap attributable to dissimilation is that involving clusters consisting of a sibilant to a pre- or postaspirated stop: sequences like /shk/ or /skh/ are also systematically missing. I propose to explain this by noting that, although Mazateco fricatives are not distinctively aspirated, they are clearly phonetically aspirated, as indicated by the fact that they yield /h/ under debuccalization" (Steriade 1994:246). And: "The aspiration

\footnotetext{
${ }^{18}$ We shall not discuss the place node restriction here, but note that neither (falling) diphthongs like [ai, ui, oi] nor double articulations [ $\mathrm{kp}]$ nor secondary articulated sounds [ $\left.\mathrm{p}^{\mathrm{j}}\right]$ may be single surface segments according to Steriade's formula.

${ }^{19}$ Both are mentioned in table 1 above.
} 
is clearly redundant in this case, but its phonological presence is fairy clear: no other assumption will explain the absence of /S-stop-h/" (1994:253).

If spirants like /s/ are phonetically aspirated, it is not clear how they differ from the phonologically aspirated spirants /sh, $\mathrm{Sh}$ / (recall that continuants only have a single aperture node). Again, we quote Steriade's discussion in full, as it shows how much her analysis relies on a number of intermediate steps as well as the need for a nucleic solution for the postconsonantal laryngeal features.

[T] he analysis of aspirated continuants $/ \mathrm{sh} /, / \mathrm{fh} /, / \mathrm{hh} /$ is based on the hypothesis that aspiration becomes simultaneous with the features of the existing A-position. We claimed that the distinction between surface /s/ and $/ \mathrm{sh} /$ is not that between a single segment and a cluster but rather between a plain unaspirated consonant and its aspirated counterpart. Since this requires that surface $/ \mathrm{s} /$ and $/ \mathrm{s} /$ be unaspirated, we seem to have derived a contradiction.

The solution is this. Vowels are laryngealized after $/ 7 /$ and aspirated after $/ \mathrm{h} /$, as noted, in the case of laryngealization, by PP (1947:79-80) and demonstrated, for aspiration and laryngealization, by Kirk, Ladefoged and Ladefoged (1984) ${ }^{20}$ However, no amount of vocalic aspiration is reported after the plain spirants or affricates and the instrumental data reported by Kirk, Ladefoged and Ladefoged indicates that the plain, unaspirated, fricatives and affricates (i.e., $/ \mathrm{s} /, / \mathrm{J} /, / \mathrm{ts} /, / \mathrm{t} / \mathrm{l} / \mathrm{ts} /$ ) do not induce aspiration of the following vowel. This suggests that only distinctive laryngeal features spread onto following vowels. (1994:253-54)

The contrast between what $\mathrm{PP}$ transcribed as $/ \mathrm{sh} /$ and $/ \mathrm{s} /$ exists, but resides in the vocalic context rather than the consonantal articulation. (1994:255)

Thus, according to Steriade, Huautla has a contrast between distinctively and redundantly aspirated fricatives, which differ phonetically in the amount of voicelessness within the following vowel. This is seen as evidence for a rule-ordering approach, where distinctively aspirated fricatives merge from underlying clusters and spread their laryngeal features to adjacent vowels before all other fricatives are redundantly aspirated (the latter may be blocked by distinctive glottalization). How this scenario accounts for the absence of underlying /S-stop-h/ "clusters" is not clear to us in any case.

For us, onsets like PP's [hts'] and [ht '?] are minor exceptions to the restriction in (13) that disallows adjacent laryngeally specified onsets and nuclei. Given that all other constraints we listed in (16) are violated occasionally, we expect minor exceptions to (13) as well, especially since they

\footnotetext{
${ }^{20}$ Kirk, Ladefoged, and Ladefoged (1993) do not demonstrate that vowels "are laryngealized after /// and aspirated after /h/" as Steriade claims. Rather they claim quite clearly that vowels are DISTINCTIVELY aspirated and glottalized.
} 
are rare and tend to vary to $/ \mathrm{ts} \%$ and $/ \mathrm{t} \int \%$. In our analysis, Huautla fricatives do not bear contrastive laryngeal specifications of any kind and there is no "spreading" of laryngeal features into the middles of vowels because these features already belong to the nucleus phonologically. This solution strikes us as more economical and as more plausible phonetically.

5. Conclusion. As we see it, Huautla Mazatec offers no evidence for the complex syllable structure proposed by Pike and Pike. In particular, we see no evidence in Huautla that segments are extrinsically ordered within the onset or nucleus, the fundamental claim of their analysis. Similarly for plosives: we see no evidence in Huautla (or any other language) that laryngeal features can be extrinsically ordered within a plosive, the central claim of Steriade's aperture theory. If our analysis of Huautla is correct, there is no contrast between pre- and postglottalization or between pre- and postaspiration, just as there is no contrast between pre- and postnasalization: this language does not have a single contrast that provides support for aperture theory. Instead, Mazatec is a language with fairly simple syllable structure and a highly symmetrical use of a restricted set of features for onsets and nuclei. What makes it special is that some of the phonological contrasts are difficult or even impossible to perceive if realized simultaneously: laryngeal gestures and tone in the nucleus, laryngeal gestures and complete closure in the onset. That is why they are realized in complex ways-but the basic contrasts are simple and of the kind we find in many other languages.

\section{RFERENCES}

Ballard, W. L. 1975. Aspects of Yuchi morphonology. Studies in Southeastern Indian Languages, ed. James M. Crawford, pp. 163-87. Athens: University of Georgia Press.

Black, ANDrew H. 1991. The phonology of the velar glide in Axininca Campa. Phonology 8:183-217.

BROAdBENT, Judith. 1991. Linking and intrusive $r$ in English. University College London Working Papers in Linguistics 3:281-302.

BuCKLEY, Eugene. 1990. Glottalized and aspirated sonorants in Kashaya. Occasional Papers in Linguistics: Papers from the 1990 Hokan-Penutian Language Workshop, ed. James E. Redden. Carbondale: Department of Linguistics, Southern Illinois University.

1992. Kashaya laryngeal increments, contour segment and the moraic tier. Linguistic Inquiry 23:487-96.

1993. On aperture and increments. Ms., University of Pennsylvania.

CRAWFORD, JAMES M. 1973. Yuchi phonology. IJAL 39:173-79.

Golston, Chris, AND HARRY VAN DER Hulst. Forthcoming. Stricture is structure. The Derivational Residue, ed. Ben Hermans and Marc van Oostendorp. Amsterdam: Benjamins.

GnANADEsikan, Amalia E. 1993. The feature geometry of coronal subplaces. University of Massachusetts Occasional Papers in Linguistics 16:27-67. 
GREENBERG, JOSEPH. 1970. Some generalizations concerning glottalic consonants, especially implosives. IJAL 36:123-45.

Gudschinsky, SARAH C. 1953. Proto-Mazatec. Memoria del Congreso Científico Mexicano $12: 171-74$

1959. Proto-Popolocan: A Comparative Study of Popolocan and Mixtecan. Indiana University Publications in Anthropology and Linguistics, no. 5. Baltimore: Waverly Press.

Hall, Tracy Alan. 1993. The Phonology of German /R/. Phonology 10:83-105.

. 1995. Palatale Laute und das Merkmal [koronal]. Lecture given at the annual meeting of the Deutsche Gesellschaft für Sprachwissenschaft, Göttingen.

Hume, ElisabeTh. 1992. Front vowels, coronal consonants and their interaction in nonlinear phonology. Ph.D. dissertation, Cornell University.

Jamieson, A. 1977a. Chiquihuitlan Mazatec Phonology. Studies in Otomanguean Phonology, ed. W. Merryfield, pp. 93-105. Dallas: Summer Institute of Linguistics.

1977b. Chiquihuitlan Mazatec tone. Studies in Otomanguean Phonology, ed. W. Merryfield, pp. 107-36. Dallas: Summer Institute of Linguistics.

JesPersen, OtTo. 1904. Lehrbuch der Phonetik. Leipzig and Berlin.

Jones, Ted, ANd Lyle M. Knudson. 1977. Guelavia Zapotec phonemes. Studies in Otomanguean Phonology, ed. W. Merryfield, pp. 163-80. Dallas: Summer Institute of Linguistics.

Keating, PATricia, AND Aditi LAhiRI. 1993. Fronted velars, palatalized velars, and palatals. Phonetica 50:73-101.

Kingston, John. 1990. Articulatory binding. Papers in Laboratory Phonology I: Between the Grammar and Physics of Speech, ed. J. Kingston and M. E. Beckman, pp. 406-34. Cambridge: Cambridge University Press.

Kirk, Paul; Jenny Ladefoged; and Peter Ladefoged. 1993. Quantifying acoustic properties of modal, breathy and creaky vowels in Jalapa Mazatec. American Indian Linguistics and Ethnography in Honor of Laurence C. Thompson, ed. A. Mattina and T. Montler, pp. 435-50. Missoula: University of Montana.

Ladefoged, Peter, and Ian Maddieson. 1996. The Sounds of the World's Languages. Oxford: Blackwell.

LEBEN, Will. 1973. Suprasegmental phonology. Ph.D. dissertation, Massachusetts Institute of Technology.

Longacre, Robert E. 1957. Proto-Mixtecan. Publications of Indiana University Research Center in Anthropology, Folklore, and Linguistics, no. 5. Bloomington: Indiana University.

LyMAN, LARRY, AND RoSEMARY LyMAN. 1977. Choapan Zapotec phonology. Studies in Otomanguean Phonology, ed. W. Merryfield, pp. 137-61. Dallas: Summer Institute of Linguistics.

Maddieson, IAN. 1984. Patterns of Sounds. Cambridge: Cambridge University Press.

MCCARTHY, JOHN J. 1986. OCP effects: gemination and antigemination. Linguistic Inquiry 17:207-63.

1988. Feature geometry and dependency: a review. Phonetica 43:84-108.

PANDIT, P. B. 1957. Nasalization, aspiration and murmur in Gujarati. Indian Linguistics $17: 165-72$.

Picketr, Velma B.; ET AL. 1959. Castellano-Zapateco, Zapateco-Castellano, dialecto del Zapateco del Istmo. Mexico City: Summer Institute of Linguistics.

Pike, Kenneth L., And Eunice Pike. 1947. Immediate constituents of Mazatec syllables. IJAL 13:78-91.

Pulleyblank, E. G. 1989. The role of coronal in articulator based features. Papers from the Chicago Linguistics Society 25:379-93.

Rensch, Calvin R. 1976. Comparative Otomanguean Phonology. Language Science Monographs, vol. 14. Bloomington: Indiana University. 
RICE, KEREN. 1993. A reexamination of the feature [sonorant]: the status of 'sonorant obstruents'. Language 69:308-44.

Sievers, Eduard. 1881. Grundzüge der Phonetik. Leipzig: Breitkopf and Hartel.

Silverman, Daniel. 1994. A case study in acoustic transparency: [spread glottis] and tone in Chinantec. Proceedings of the Northeastern Linguistic Society 24, no. 2:559-72.

Spring, CARI. 1992. The velar glide in Axininca Campa. Phonology 9:329-52.

Stark, Sharon, and Polly Machin. 1977. Stress and tone in Tlacoyalco Popoloca. Studies in Otomanguean Phonology, ed. W. Merryfield, pp. 69-92. Dallas: Summer Institute of Linguistics.

STERIADE, DonCA. 1993. Segments, contours and clusters. Proceedings of the XVth International Congress of Linguistics, ed. André Crochetière, Jean-Claude Boulanger, and Conrad Ouellon. Sainte-Foy: Les presses de l'université Laval. . 1994. Complex onsets as single segments: the Mazateco pattern. Perspectives in Phonology, ed. J. Cole and C. Kisseberth, pp. 203-91. Stanford, Calif.: Center for the Study of Language and Information.

Traill, Anthony. 1985. Phonetic and Phonological Studies of !Xóõ Bushman. Hamburg: Helmut Buske.

WaGner, Günter. 1931. Yuchi Tales. Publications of the American Ethnological Society, vol. 13. New York: G. E. Stechert and Co. 1934. Yuchi. Handbook of American Indian Languages, vol. 3, ed. F. Boas, pp. 293384. New York.

WOLFF, H. 1948. Yuchi phonemes and morphemes. IJAL 14:240-43. 